\title{
Successful treatment of chronic active T-cell-mediated rejection after high-dose immunoglobulin administration in BK virus nephropathy not responding to immunosuppressant reduction:
} a case report

\author{
Joon Seok Oh, Tae Hyun Ryu, Hee Yeon Kim, Joong Kyung Kim \\ Department of Internal Medicine-Nephrology, Bongseng Memorial Hospital, Busan, Korea
}

Background: BK virus nephropathy, which occurred after a kidney transplant, has not yet established a clear treatment. In the absence of a specialized antiviral drug for BK virus, there is a concern of a concurrent rejection reaction when immunoglobulin is administered to reduce or neutralize immunosuppressants. The authors report that they have experienced successful treatment of the chronic active T-cell-mediated rejection, which occurred four months after administering high dose immunoglobulin to BK virus nephropathy, which deteriorates in the reduction and modification of immunosuppressants.

Case report: A 28-year-old male patient with end-stage renal disease was hospitalized three months after receiving a deceased donor kidney transplant with elevated serum creatinine. A biopsy of the transplanted kidney was diagnosed as BK virus nephropathy stage A (Banff score: i1 ci1 ct1 ah2 i IF/TA2 ti2 as3). At the time of diagnosis, the BK viral load was 6 log copies/mL in serum, and 9 log copies/mL in urine. Immediately, mycophenolate was discontinued, and tacrolimus was changed to sirolimus. After 1 month, the patient's serum creatinine continued to increase, and high-dose immunoglobulin $(2 \mathrm{~g} / \mathrm{kg})$ was administered, and a gradual decrease in serum creatinine was observed. After 2 months of immunoglobulin administration, serum BK virus DNA polymerase chain reaction was negative and showed improvement clinically. Two months later, he was hospitalized due to elevated serum creatinine, and a graft biopsy was performed again. Graft kidney biopsy showed chronic active T-cell-mediated rejection, grade 1B (Banff i0 t3 ci3 ct3 ptc1 i IF/TA3). Sirolimus was changed back to tacrolimus, mycophenolate was added again, and steroid pulse treatment was performed.

Conclusions: After that, a gradual decrease in serum creatinine was observed over 1 year, and it has now decreased to a normal level. The patient is currently under observation at the outpatient clinic.

Corresponding author: Joon Seok Oh

E-mail: j-seok@hanmail.net

(c) The Korean Society for Transplantation

This is an Open Access article distributed under the terms of the Creative Commons Attribution Non-Commercial License (http://creativecommons.org/licenses/by-nc/4.0/) which permits unrestricted non-commercial use, distribution, and reproduction in any medium, provided the original work is properly cited. 